\title{
Corrigendum: Structural snapshots of concerted double E-H bond activation at a transition metal centre
}

Joseph A. B. Abdalla, Alexa Caise, Christian P. Sindlinger, Rémi Tirfoin, Amber L. Thompson, Alison J. Edwards and Simon Aldridge

Nature Chemistry 9, 1256-1262 (2017); published online 12 June 2017; corrected after print 18 December 2017.

References 23-27 and 31-38 in the introductory paragraphs describe literature precedent for the activation of two E-H bonds at a transition metal centre (for $\mathrm{E}=\mathrm{B}$ or $\mathrm{C}$ ). It should be noted that experimental precedent also exists for the analogous activation of $\mathrm{Si}-\mathrm{H}$ bonds and the manuscript has been modified to include additional citation of this chemistry (refs 22, 28-30).

\section{References}

22. Lipke, M. C., Liberman-Martin, A. L. \& Tilley, T. D. Electrophilic activation of silicon-hydrogen bonds in catalytic hydrosilations. Angew. Chem. Int. Ed. 56, 2260-2294 (2017).

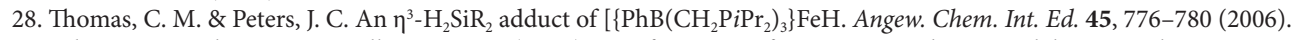

29. Faluso, M. E., Glaser, P. B. \& Tilley, T. D. Cp* $\left(\mathrm{P} i \mathrm{Pr}_{3}\right) \mathrm{RuOTf}$ a reagent for access to ruthenium silylene complexes. Organometallics 30, $5524-5531$ (2011).

30. Faluso, M. E., Lipke, M. C. \& Tilley, T. D. Structural and mechanistic investigation of a cationic hydrogen-substituted ruthenium silylene catalyst for alkene hydrosilation. Chem. Sci. 4, 3882-3887 (2013). 